\title{
Osteoma of Frontal Sinus. Report of a Clinical Case
}

\author{
Rangachev Yu., M. Tsekova, T. Popov \\ Tsaritsa Yoanna-ISUL University General Hospital for Active Treatment, \\ Medical University - Sofia
}

\section{Introduction}

Osteoma is the most common benign tumor of nose and paranasal sinuses, and its most frequent localization is the frontal sinus. This tumor has usually asymptomatic progress, and it may be found as an accidental finding on imaging examinations; its growth may result in the occurrence of symptoms or, although rarely, it may manifest with complications, which are due to its localization near the orbit and anterior cranial fossa.

\section{History}

Viega was the first physician, who documented sinus osteoma in 1506. Vallisnieri described osteoma of frontal sinus, which penetrated the frontal lobe of cerebrum, in 1733.

\section{Epidemiology}

The osteomas are the most common benign tumors of sinuses and are frequently found in patients, who undergo imaging examinations, mostly computed axial tomography of sinuses. They manifest in up to $3 \%$ of examinations by computed axial tomography of paranasal sinuses ${ }^{2}$. They are most frequently diagnosed in middle-aged patients (20-50 years), and more often in men $(\text { male }: \text { female }=1.5-2.6: 1)^{2}$.

\section{Etiology}

There are three theories accepted for the etiology of osteomas:

1. Disturbance of development: The first theory of disturbance of development is based on the conception that the tissues in adults contain embryonic remnants, which are usually in latent state. These remnants are activated and can transform into a neoplasm.

2. Traumatic theory: This theory postulates that bone trauma may be the main cause of bone tumor formation. Sayan et al. emphasized that the sites of predisposition of osteomas in the mandible are the areas of insertions of the muscles to the bone. Even insignificant traumas can induce subperiosteal inflammatory process of these bones. The inflammation, together with the permanent traction applied by the muscles, may lead to osteoma formation. This could also coincide with the higher frequency of osteomas recorded in men.

3. Infectious theory: This theory presumes that osteitis, as a result of chronic infections, can lead to bone tumor formation in paranasal sinuses.

\section{Pathology}

Osteoma could be smooth or made up of lobes. Although rarely, it may grow in the sinus with a thick pedicle. It is usually covered with intact sinus mucosa. There are three histological types of osteoma:

1 Compact type of osteoma

2. Cancellous type of osteoma

3. Mixed type of osteoma

1. The compact type of osteoma ("ivory" osteomas) is also known as eburneous osteoma. The bone in this type of osseous tumor is very dense and 
compact, and has no haversian canals. It grows from membranous elements of the bone.

2. Cancellous osteoma (osteoma spongiosum): It is also known as mature osteoma and consists of softer bone tissue. This type of osteomas are known for their ability to develop from cartilaginous elements. These osteomas contain scanty medular components, consisting of fibrotic and adipose tissue.

3. Mixed type of osteoma: This type contains elements of the first two types - the compact and the cancellous osteoma.

\section{Distribution}

The osteomas are also frequently found in other regions of the head and neck, especially in the mandible and external part of cranial cavity. There is a specific distribution of the frequency of localization within the paranasal sinuses ${ }^{2-4}$ :

- frontal sinuses: $80 \%$ (mainly on the floor level of the frontal sinuses)

- ethmoidal air cells: approximately $15 \%$

- maxillary sinuses: approximately $5 \%$

- sphenoidal sinus: rarely ${ }^{2}$

\section{Association with Gardner's syndrome}

There is a well-known relation of osteomas with Gardner's syndrome ${ }^{2}$. (It was first described by Gardner and Richards ${ }^{4}$ in 1953. Approximately $30 \%$ of the patients had history of rhinosinusitis, although no casual relationship was found ${ }^{2}$ ). The Gardner's syndrome is one of the so called polyposis syndromes. There is an autosomal dominant inheritance (chromosome $5 q$ ) of the syndrome of familial adenomatous polyposis in most of the patients. It is marked by:

- syndrome of familial adenomatous polyposis of the colon

- multiple osteomas especially of the bones of the mandible, cranium, and long bones

- epidermal cysts

- fibromatosis

- desmoid tumors of the abdominal wall

Other disturbances include:

- presence of supernumerary teeth

- duodenal tumors ${ }^{4}$ (carcinomas of the rectal ampulla $\left.{ }^{3}\right)$

- papillary carcinomas of the thyroid gland

\section{Clinical manifestations and symptoms}

Most osteomas are asymptomatic and are found accidentally during imaging examinations of the sinuses or in connection with complaints and symptoms from the sinonasal area, or other complaints that are not related.

The osteomas become symptomatic in one of the following two cases:

1. Direct mass effect (it leads to headache with three possible mechanisms of pain: local effect, pain through the trigeminal nerve, and prostaglandin E-2 mediated mechanism ${ }^{6}$ ).

2. Obstruction of the normal sinus drainage.

As a result the following manifestations also occur:

1. Diplopia.

2. Facial deformation.

3. Sinusitis (acute or chronic).

4. Formation of mucocele.

Some osteomas a big and exophytic. They may even been found upon palpation (in particular the osteomas of calvarium) or can compress the adjacent structures, e.g. the orbit content ${ }^{2-4}$. Although rarely, a bone tumor can penetrate into the cerebrum, and even lead to erosion of dura mater with subsequent liquorrhea, pneumocele, intracranial infection (meningitis, cerebral abscess, etc.) ${ }^{2-3,5}$. It may more frequently disturb the normal drainage of one or more sinuses, which leads to acute or chronic sinusitis or even to mucocele formation ${ }^{2,4}$.

\section{Diagnosis}

Imaging examinations

The plain radiographs are appropriate for finding of osteomas of paranasal sinuses. They demonstrate the osteomas as a dense, homogeneous mass that is well delineated from the surrounding tissues. Computed tomography is more sensitive for proving of small osteomas. Magnetic resonance imaging scanning can be helpful for exclusion of intracranial engagement.

\section{Radiographic finding}

The radiographic image of osteoma resembles a dense, well-outlined and contoured tumor mass. The compact osteomas ("ivory" osteomas) are uniformly dense, and the mature or cancellous osteomas can resemble „normal“ bone, sometimes with visible space of the medullary cavity. 

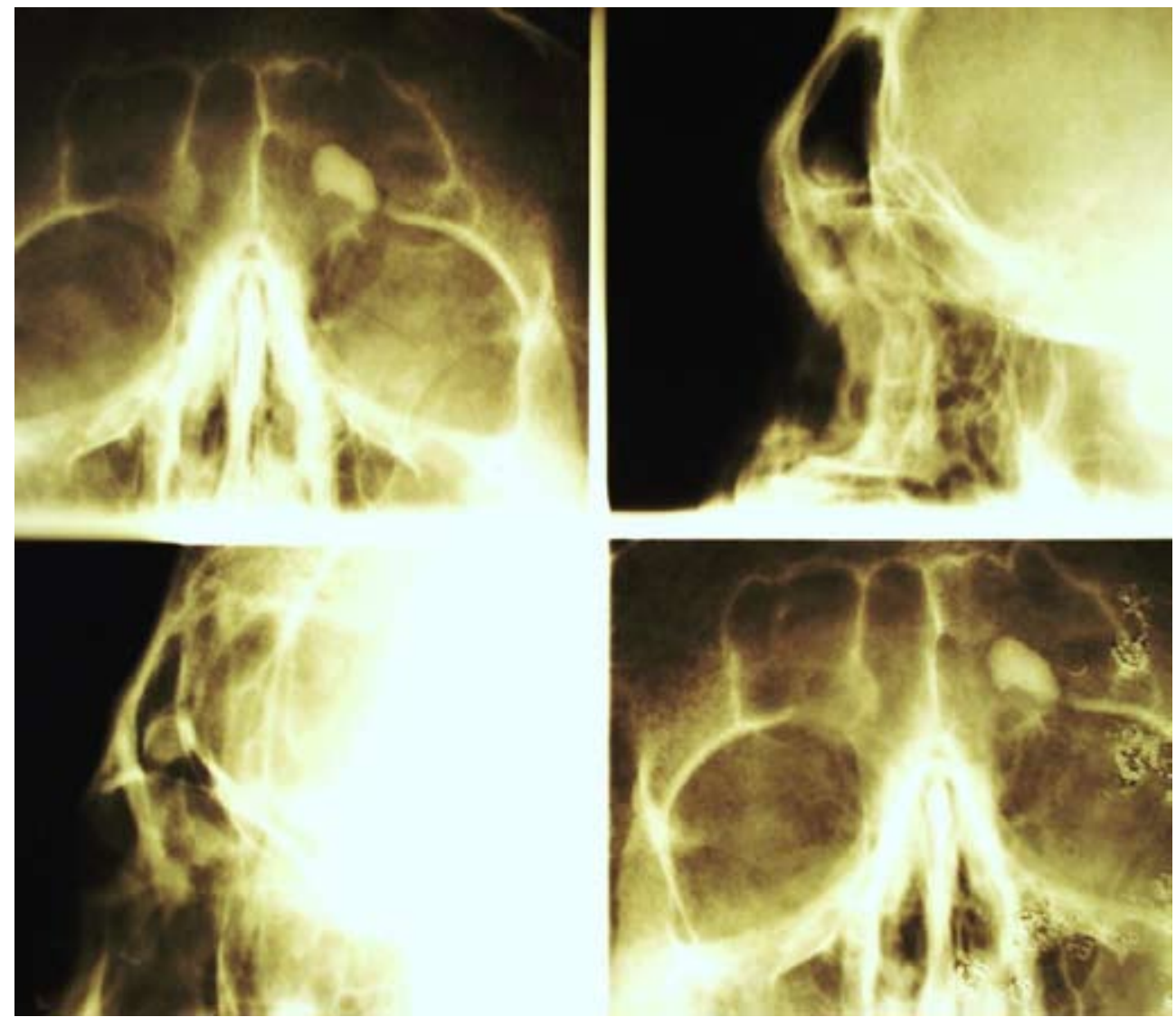

Figure 1. A radiograph of compact osteoma.

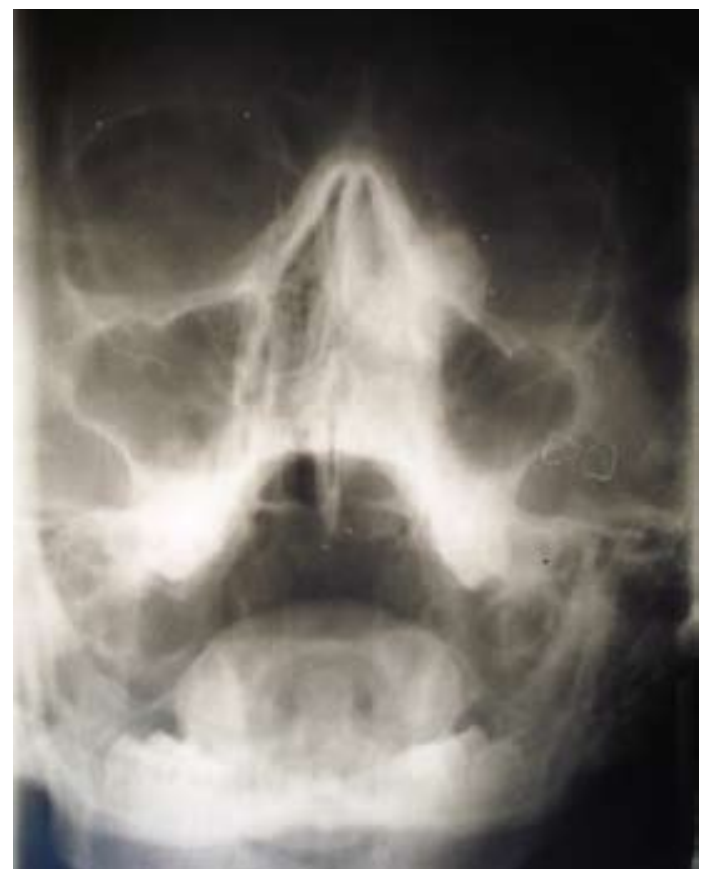

Figure 2. A radiograph of mixed osteoma (frontal view).

\section{Imaging examinations - computed tomography}

The computed tomography demonstrates well-outlined mass of variable density - it varies from very

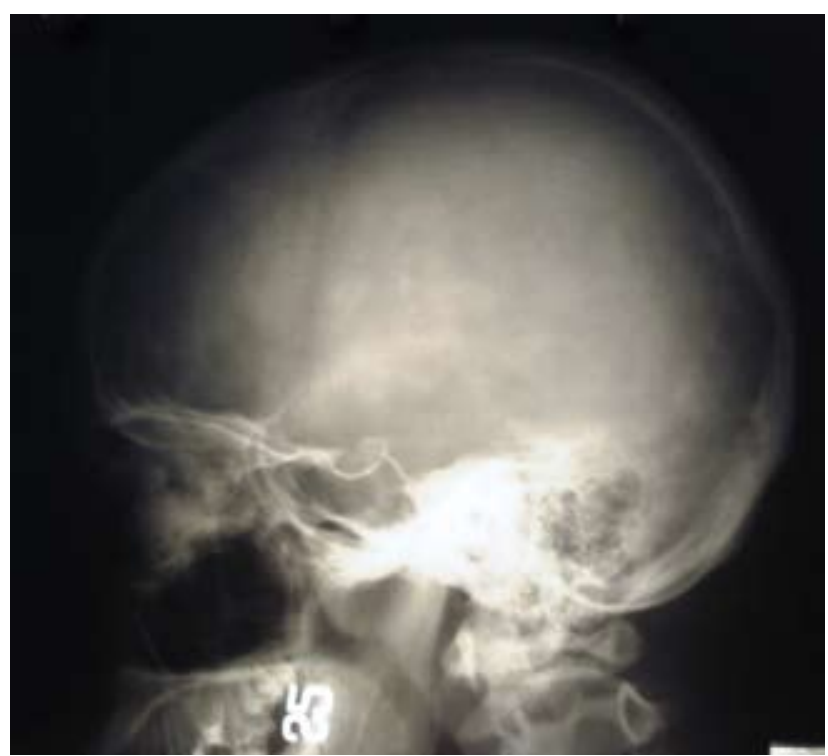

Figure 3. A radiograph of mixed osteoma (lateral view).

dense (similar to the density of normal cortical bone) to less dense with the appearance of ,ground glass". They are visualized as a formation growing inside the cavity of the sinus or, more rarely, with exophytic growth outside of the sinuses. 


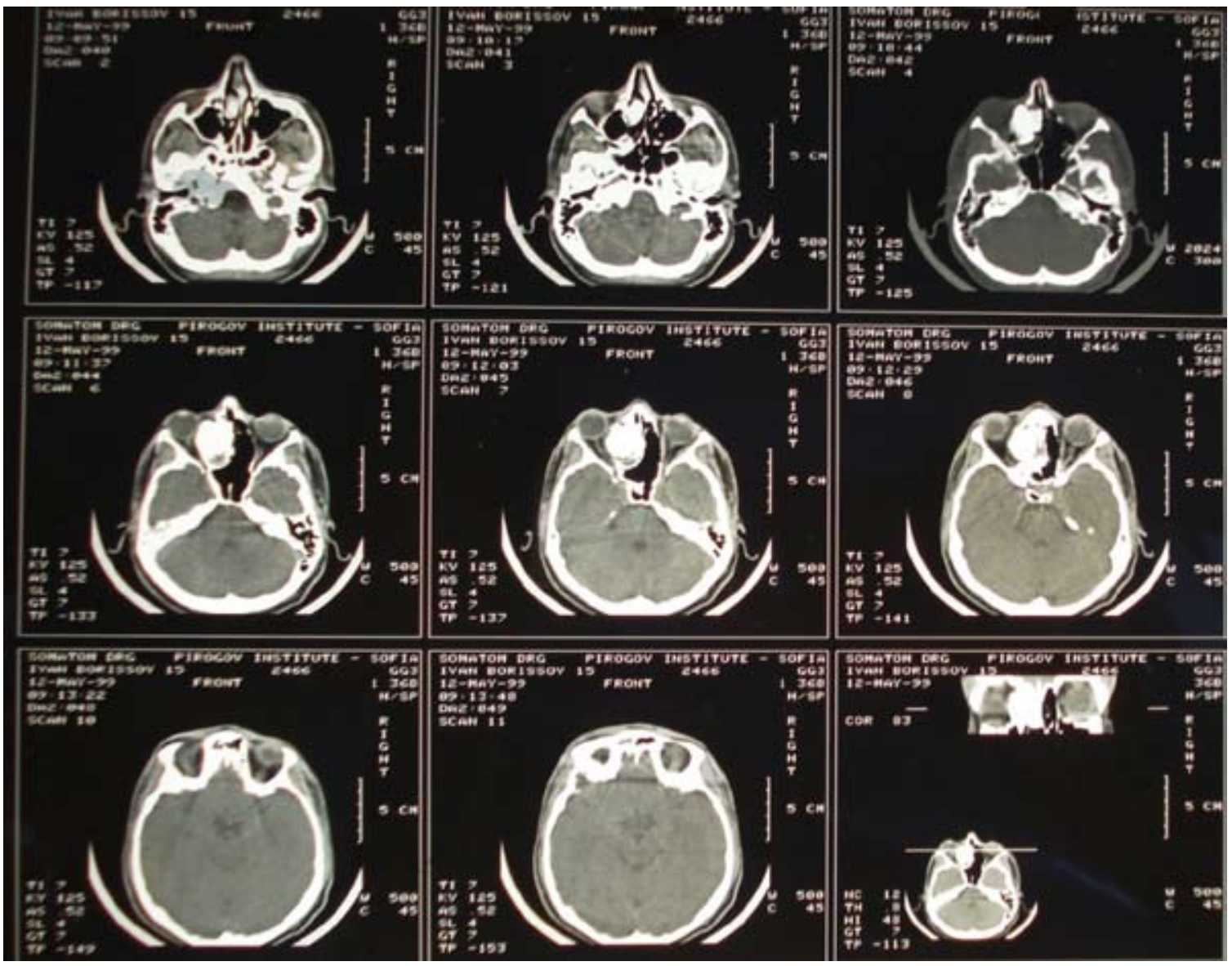

Figure 4. Computed tomography of mixed osteoma.

\section{Imaging examinations - magnetic resonance imaging}

The dense and compact osteomas have low intensity on all sequences of magnetic resonance imag- ing. The mature or compact osteomas may be demonstrated as a signal of bone marrow, but also have predominantly low intensity on all sequences.

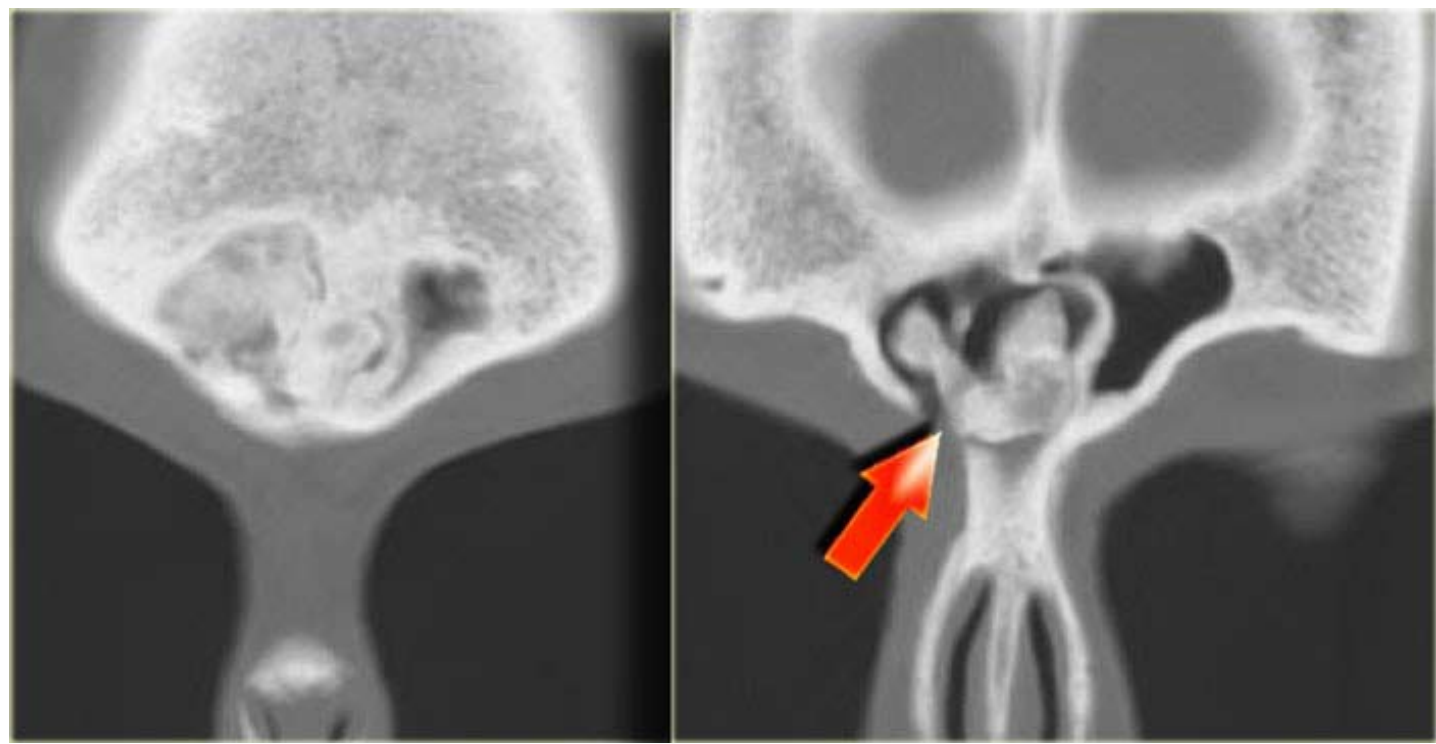

Figure 5. Paranasal sinuses - magnetic resonance imaging. Laurie Loevner and Jennifer Bradshaw; Radiology Department of the University of Pennsylvania, USA and Radiology Department of the Medical Centre Alkmaar, the Netherlands. 


\section{Treatment and prognosis}

In asymptomatic cases, the excision is not mandatory and the decision for surgical treatment depends on the surgeon. If there are symptoms from the sinonasal area, then they can be initially suppressed by administration of drugs (as if there is no osteoma). In cases, when osteoma is accepted as responsible for the symptoms (e.g. pain, sinusitis, mucocele, etc.), performing of resection is required. Some surgeons prefer removal of all osteomas found. Excision can be performed with external access or endoscopically.

\section{Differential diagnosis}

The following conditions are included as differential diagnoses, based on the imaging examinations:

- fibrotic dysplasia - especially in osteomas with less density - osteomas that resemble ,ground glass" on radiographs

- other osteogenic tumors

- osteoblastoma

- osteosarcoma - more frequently in the maxilla (than in the maxillary sinus or mandible)

- young patients

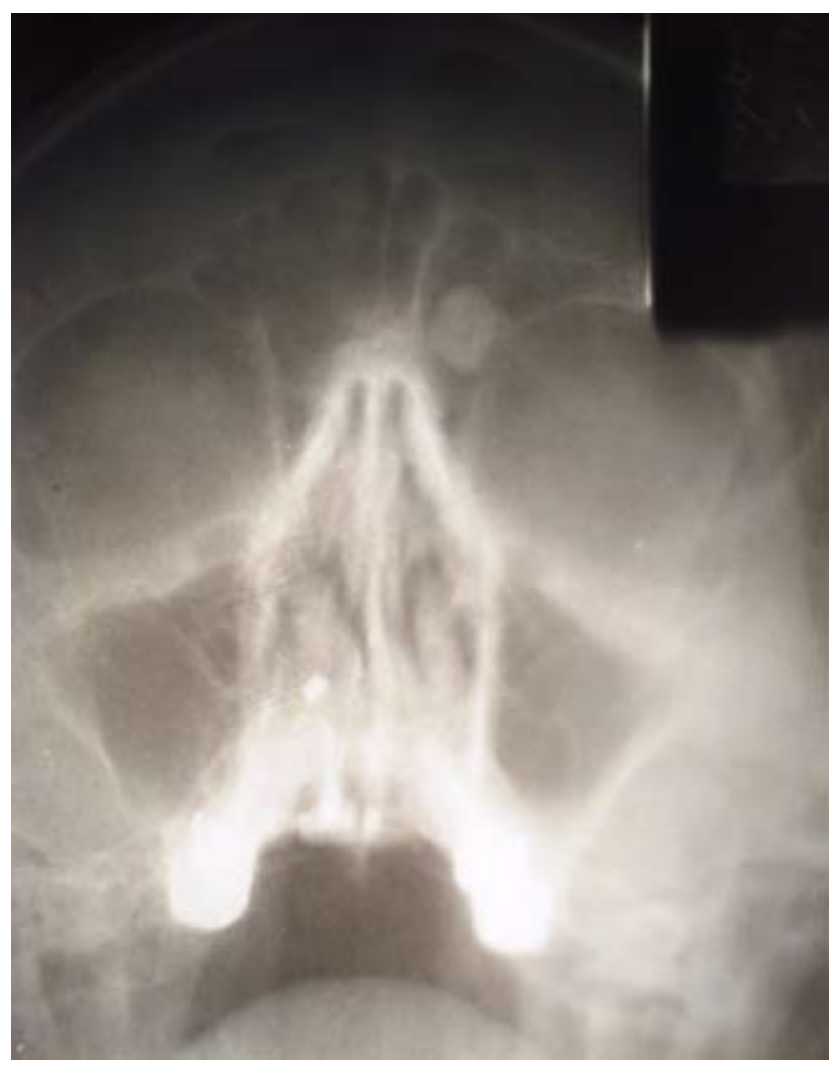

Figure 6. A preoperative radiograph (a clinical case).
- more aggressive appearance and fast growth

- cement-ossificating fibroma ${ }^{3}$

- usually engaging the alveolar sections of the mandible or maxilla

\section{Clinical case}

This is a case of a female patient at the age of 41 years with frontal headache - with onset more than a year ago - not responding as expected to non-steroid intiinflammatory drugs. Patient did not complained of nasal congestion, rhinorrhea, or other symptoms typical of the paranasal sinuses. Patient was consulted by a neurologist (for exclusion of headache with neurological genesis), and cardiologist (for exclusion of high arterial blood pressure). Due to intensification of pain, patient was directed by otolaryngologist for performing of a radiograph of paranasal sinuses, which found a shadow with bone density within the frontal sinus on the left side. Patient was directed for performing of computed tomography of paranasal sinuses, with finding of data of dense bone tumor.

Patient was operated with open access. Surgical treatment - Beck technique for trepanation of frontal sinus.

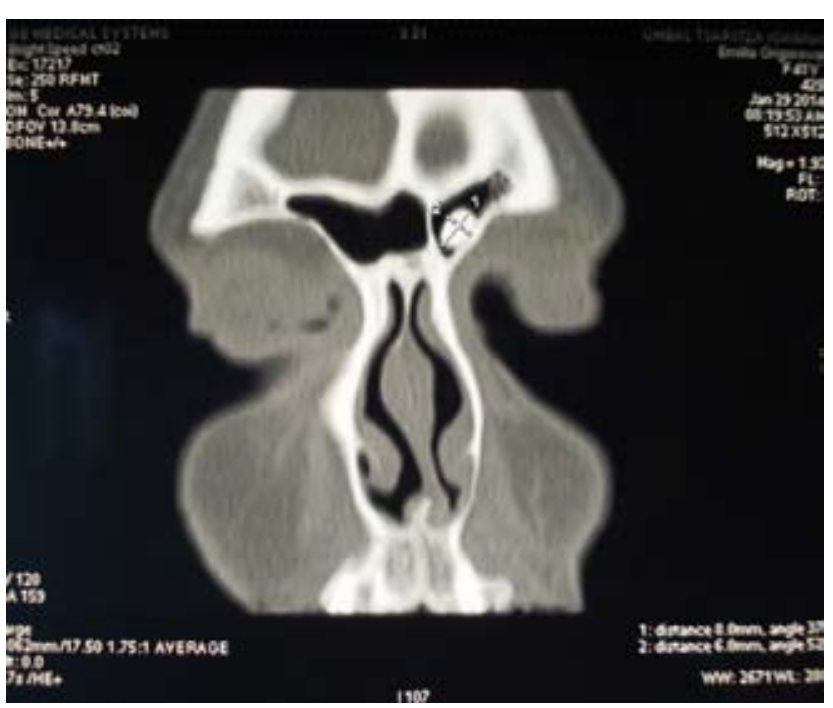

Figure 7. A preoperative computed tomography (a clinical case). 
QPil international Bulletin of $\square$ torhinolaryngology

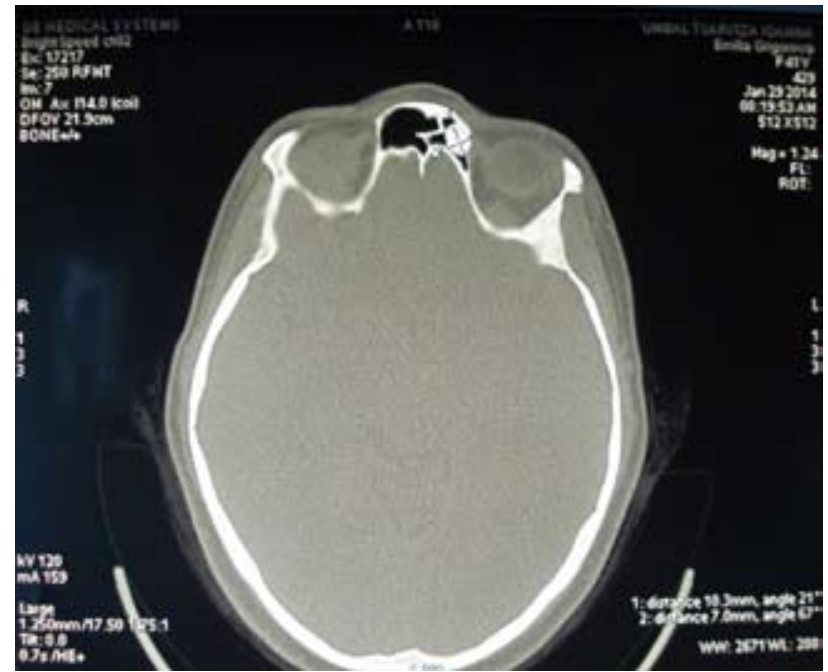

Figure 8. A preoperative computed tomography (a clinical case).

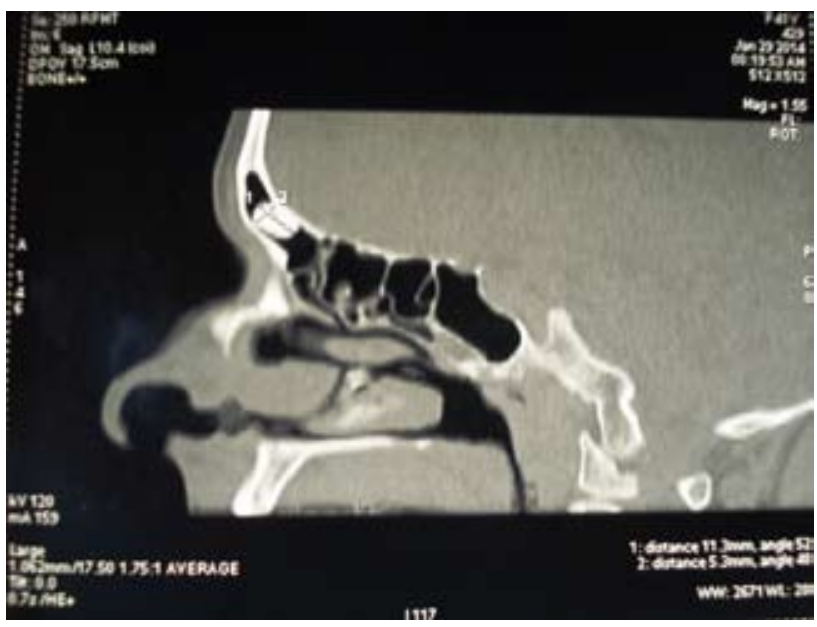

Figure 9. A preoperative computed tomography (a clinical case).

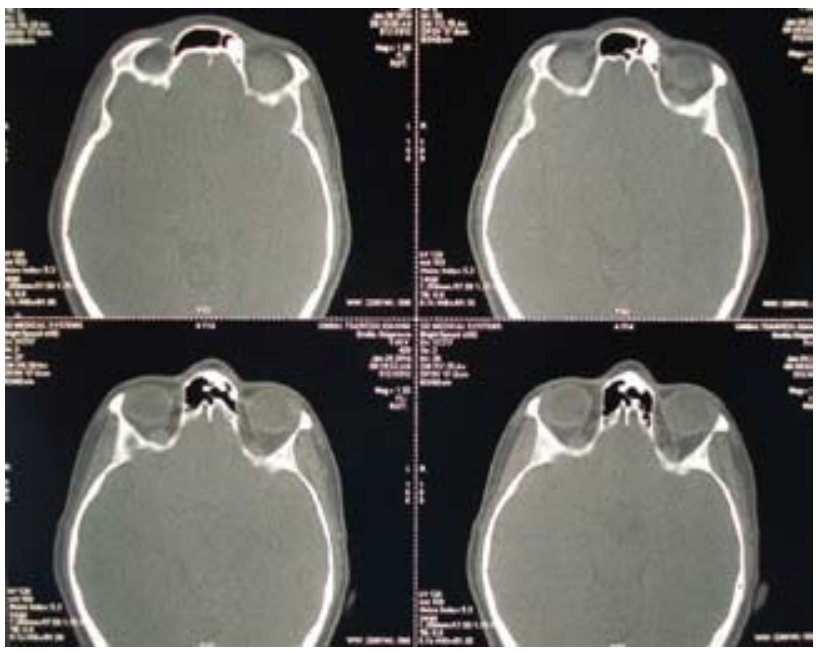

Figure 10. Preoperative computed tomography (a clinical case).

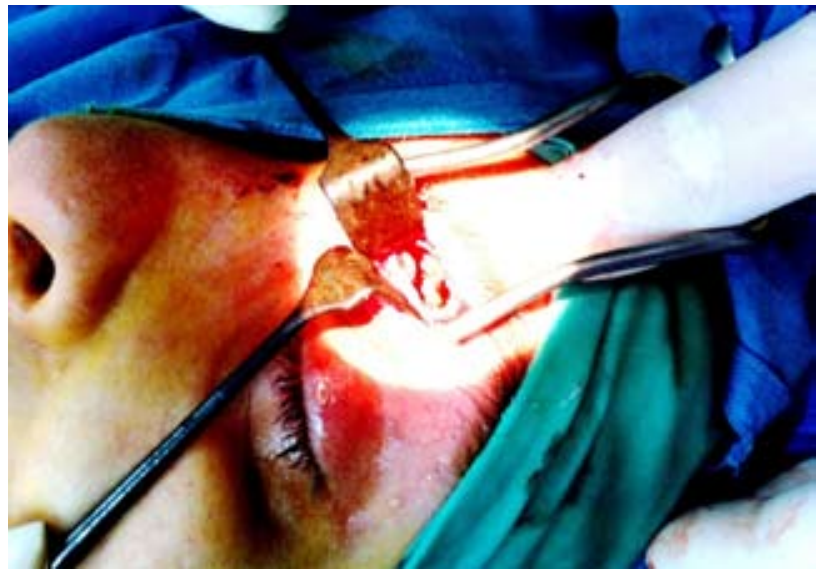

Figure 11. Surgical intervention.

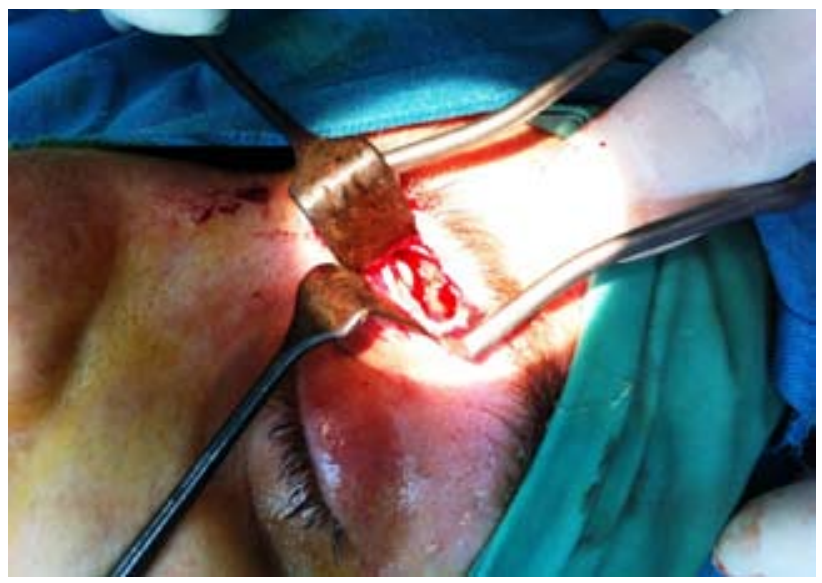

Figure 12. Surgical intervention.

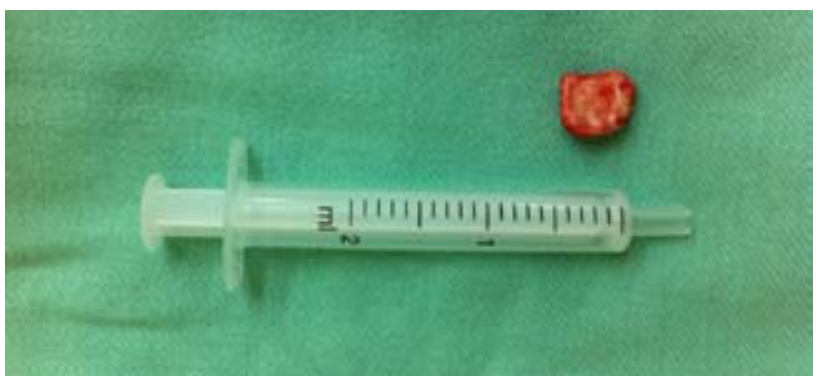

Figure 13. Postoperative finding - osteoma.

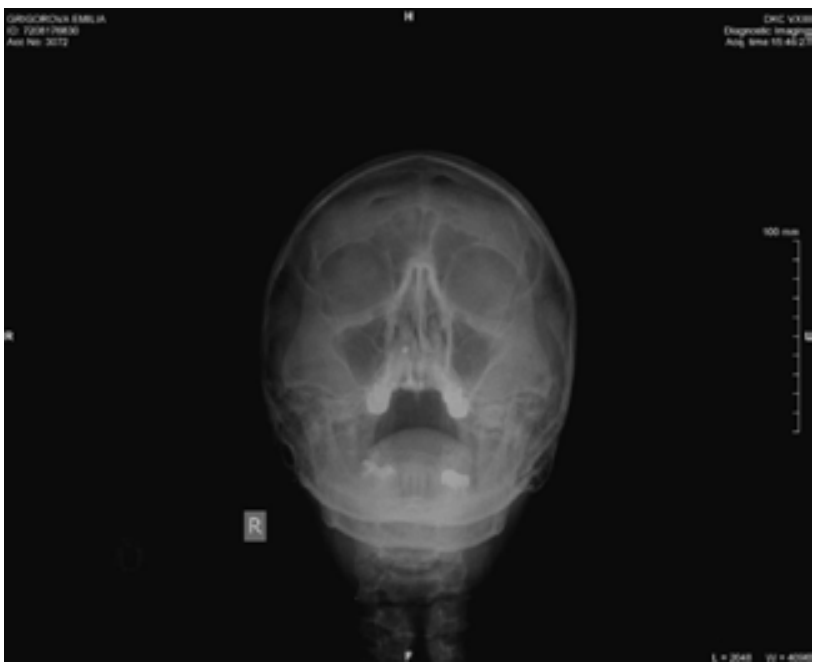

Figure 14. A postoperative radiograph. 


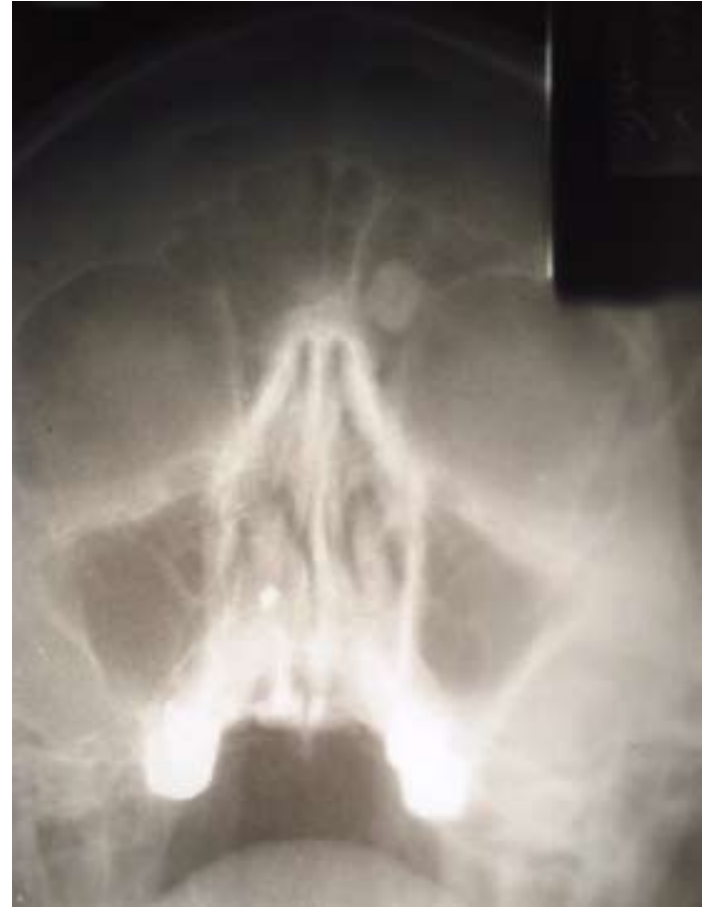

Figure 15. A radiograph before the operation.

\section{Conclusion}

\section{Summary}

Osteomas are the most common tumors of paranasal sinuses.

They are most frequently found in the frontal sinus and ethmoidal air cells.

They represent benign bone tumors originating from membranous elements of bone, consistning of dense bone tissue.

The majority of sinus osteomas are accidentally found.

When in the region of cranium, they usually occur over the bone surface.

Obstruction of the drainage openings of sinuses can lead to occurrence of infection (sinusitis) or to cause mucocele formation.

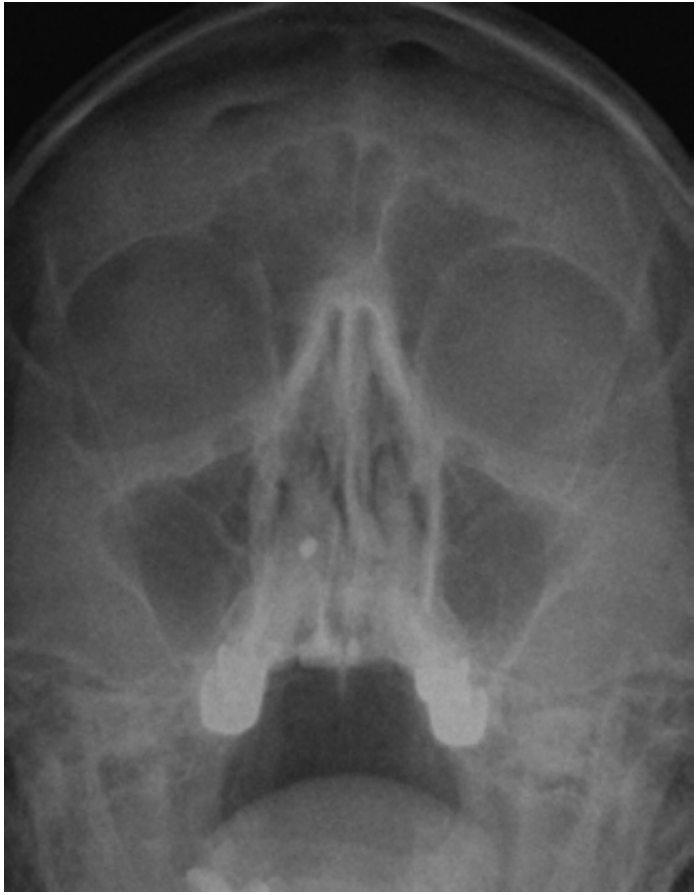

Figure 16. A radiograph after the operation.

Proptosis with replacement of the bulb of eye in frontal direction can rarely be caused by a major bone tumor of the frontal and ethmoidal labyrinthus.

Erosion of dura mater may occur very rarely, which leads to rhinoliquorrhea and/or intracranial infection.

Multiple osteomas are frequently associated with Gardner's syndrome.

Their excision can be performed endoscopically or surgically by an open access.

Removal of the asymptomatic osteomas is not necessary. They do not relapse once they have been removed radically.

\section{References}

1. Tsenev, Iv.; Clinical and morphological rhinolaryngology; 2003; pp. 202-203

2. Paranasal sinus osteoma; Dr MT Niknejad and Dr Frank Gaillard et al./ 1. Maroldi R, Nicolai P, Antonelli AR. Imaging in treatment planning for sinonasal diseases. Springer Verlag. (2005) ISBN:3540423834. Read it at Google Books - Find it at Amazon

3. Chen CY, Ying SH, Yao MS et al. Sphenoidal sinus osteoma at the sella turcica associated with empty sella: CT and MR imaging findings. AJNR Am J Neuroradiol. 2008; 29 (3): 550-1. doi:10.3174/ajnr.A0935 - Pubmed citation

4. Maxillofacial Imaging. T.A. Larheim, P.-L. Westesson. Springer ISBN: 3540786856 (find it at amazon.com)

5. Hsu CC, Kwan GN, Bhuta SS. Non-traumatic cerebrospinal fluid rhinorrhea caused by ethmoid sinus osteoma. J Clin Neurosci. 2010; 17 (9): 1185-6. doi:10.1016/j.jocn.2009.11.028 - Pubmed citation

6. Kim KS. Frontal Headache Induced by Osteoma of Frontal Recess. Headache. 2013; Headache (full text) - doi:10.1111/head.12029 - Pubmed citation

7. ENDOSCOPIC REMOVAL OF FRONTOETHMOID OSTEOMA: A CASE REPORT; Murat Sarı, Tekin Bağlam, Zahide Mine Yazıcı, Cüneyd Üneri; Department of Otorhinolaryngology, School of Medicine, Marmara University, İstanbul, Turkey; Marmara Medical Journal.

8. Malignant Tumors of the Sinuses; in eMedicine by Gerard Domanowski.

9. The Silent Sinus Syndrome by Anna Illner et al. AJR 2002; 178: 503-506. http://www.ajronline.org/cgi/content/full/178/2/503

10. http://www.learningradiology.com/misc/contactlegalpage.htm 


\title{
Остеома на фронталния синус. Представяне на клиничен случай
}

\author{
Рангачев Ю., М. Цекова, Т. Попов \\ УМБАЛ „Царица Йоанна-ИСУЛ“, МУ - София
}

\section{Въведение}

Остеома е най-често срещаният доброкачествен тумор на носа и околоносните кухини и фронталният синус е най-честата му локализация. Този тумор обикновено протича асимтоматично и може да бъде открит като случайна находка на образни изследвания или неговият растеж може да доведе до появата на симптоми или да се прояви макар и рядко с усложнения, което се дължи на неговото местоположение в близост до орбитата и предната черепна яма.

\section{История}

Viega е първият, който документира синусната остеома през 1506 г. През 1733 година Vallisnieri описва остеома на фронталния синус, проникващ в челния дял на мозъка.

\section{Епидемиология}

Остеомите са най-честият доброкачествен Ту на синусите и се установяват често при пациенти, подложени на образни изследвания, обикновено на КАТ на синусите, които се явяват при до 3\% от КАТ прегледи на околоносните синуси ${ }^{2}$. Найчесто се диагностицират в средна възраст (20-50 г.) и по-често при мъжете (M: F = 1.5-2.6: 1)2.

\section{Етиология}

Три са приетите теории за етиологията на остеомите:
1. Нарушение в развитието. Първата теория за нарушение в развитието се основава на концепцията, че тъканите при възрастните съдържат ембрионални остатъци, които обикновено се намират в латентно състояние. Тези остатъци се активират и могат да се превърнат в новообразувание.

2. Травматична теория. Тази теория постулира, че травма на костта може да бъде основната причина за образуването на тумор на костта. Това бе посочено от Sayan et al., че предилекционни места на остеомите на долната челюст са зоните на инсерциите на мускулите за костта. Дори незначителни травми могат да възбудят субпериостален възпалителен процес на тези кости. Възпалението заедно с постоянна тракция, прилагана от мускулатура, може да доведе до образуване на остеома. Това би могло да съвпадне и с отчетената поголяма честота на остеомите при мъжете.

3. Инфекциозна теория. Тази теория предполага, че остеит може да бъде резултат от хронични инфекции, които могат да доведат до образуването на тумор на костта в околоносните синуси.

\section{Патология}

Остеомата може да бъде гладка или лобулирана. Макар и рядко, може да бъде и на пльтно краче в синуса. Обикновено тя е покрита с интактна синусна мукоза. Хистологично има три вида остеоми. 
- Компактен тип остеома

- Спонгиозен тип остеома

- Смесен тип остеома

1. Компактен тип остеома (Ivory-тип) е известна още и като ебурниирана остеома. В този вид костен тумор костта е много пльтна - компактна, и няма Хаверсови канали. Развива се от мембранни елементи на костта.

2. Спонгиозна остеома (osteomaspongiosum). Известна още и като зряла остеома и се състои от по-мека костна тъкан. Този тип на остеоми са известни с това, че могат да възникнат от хрущялни елементи. Тези остеоми съдържат оскъдни медуларни компоненти, съдържащи фиброзна и мастна тъкан.

3. Смесен тип остеома. Този тип съдържа елементи на двата вида остеоми - компактната и спонгиозната.

\section{Разпределение}

Остеомите често се установяват и в други области на главата и шията, особено на долната челюст и външна част на черепната кухина. Съществува особено разпределение на честота в рамките на околоносните кухини ${ }^{2-4}$ :

- фронталните синуси: 80\% (предимно по пода на фронталните синуси)

- етмоидалните и клетки: 15\%

- максиларните синуси: 5\%

- сфеноидалния синус: редки ${ }^{2}$

\section{Асоцираност със синдрома на Гарднер}

Налице е добре позната връзка със синдрома на Гарднер 2 . (Първо е описано през 1953 г. от Gardner и Richards ${ }^{4}$. Приблизително 30\% от пациентите имат история на риносинуит, въпреки че причинно-следствена връзка не е била установена $\left.{ }^{2}\right)$.

Синдромът на Гарднър е един от т. нар. полипозни синдроми. Налице е автозомно-доминантно унаследяване (хромозома 5q) FAP-syndrome в по-голямата част от пациентите. Характеризира се със:

- фамилна аденополипоза на колона-FAPsyndrome

- множествени остеоми, особено на костите на долната челюст, черепа и дългите кости

- епидермални кисти

- фиброматоза

- дезмоидни тумори на коремната стена
Други нарушения включват:

- наличие на допълнителни зъби

- дуоденални тумори ${ }^{4}$ (ампуларни ректални карциноми ${ }^{3}$ )

- папиларни карциноми на щитовидната жлеза

\section{Клинични появи и симптоми}

Повечето остеоми са безсимптомни и се откриват случайно при образните изследвания на синусите или във връзка с оплаквания и симптоми от синоназалния регион или други несвързани оплаквания.

Остеомите стават симптоматични в един от двата случая:

1. Директен MassEffect (водещ до главоболие с три възможни механизми за болката: локален ефект, болка чрез троичния нерв и prostagladin Е-2 медииран механизъм ${ }^{6}$ ).

2. Обструкция на нормалния синусов дренаж

В резултат на това следват и други прояви:

1. Диплопия

2. Лицева деформация

3. Синузит (остьр или хроничен)

4. Формиране на мукоцеле.

Някои остеоми са големи и екзофитни. Те могат да бъдат дори палпируеми (остеомите на черепния свод) или да компресират прилежащи структури, напр. орбиталното съдържимо ${ }^{2-4}$. Макар и рядко, един костен тумор може да проникне в мозъка, дори може да доведе до ерозия на твърдата мозъчна обвивка с ликворея, пневмоцеле, интракраниална инфекция (менингит, мозъчен абсцес и др. $)^{2-3,5}$. По-често може да наруши нормалния дренаж на един или повече синуси, което води до остър или хроничен синузит или дори формирането на мукоцеле $\mathrm{e}^{2,4}$.

\section{Диагноза}

\section{Образни изследвания}

Обикновените рентгенови снимки са подходящи за откриване на остеомите на околоносните кухини. Те показват остеомите като плътна, хомогенна, добре ограничена от околните тькани маса. Компютърна томография е по-чувствителна за доказване на малките остеоми. MRI сканирането може да бъде от помощ, за да се изключи вътречерепно ангажиране.

\section{Рентгенографска находка}

Рентгеновият образ на остеома е като на пльтна добре очертана и отграничена Ту маса. Компакт- 
ните (Ivory-тип) остеоми са равномерно пльтни, a зрелите или спонгиозни остеоми може да наподобяват „нормална“ кост с видимо понякога костномозъчно пространство.
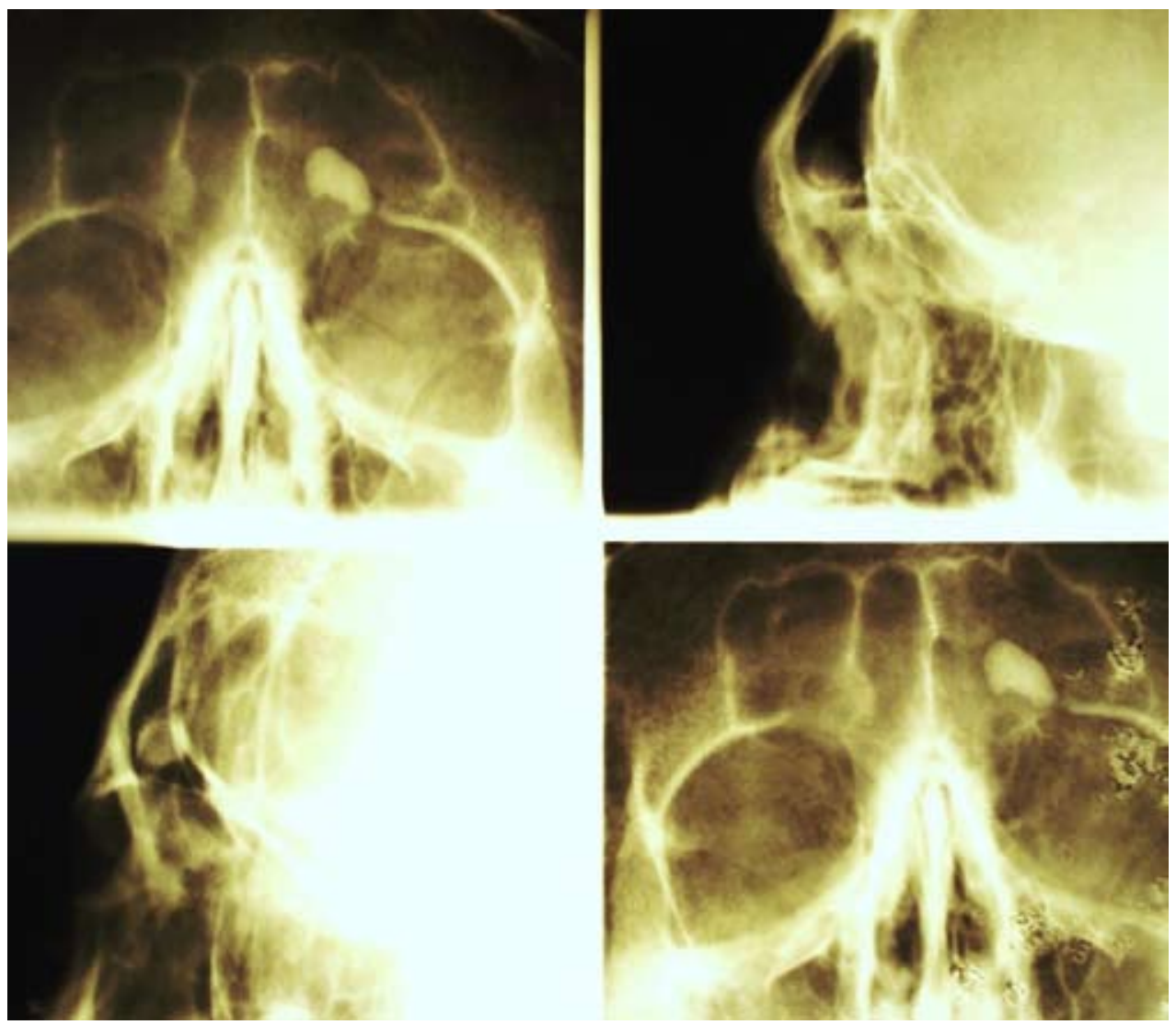

Фиг. 1. Rö-графия - компактна остеома
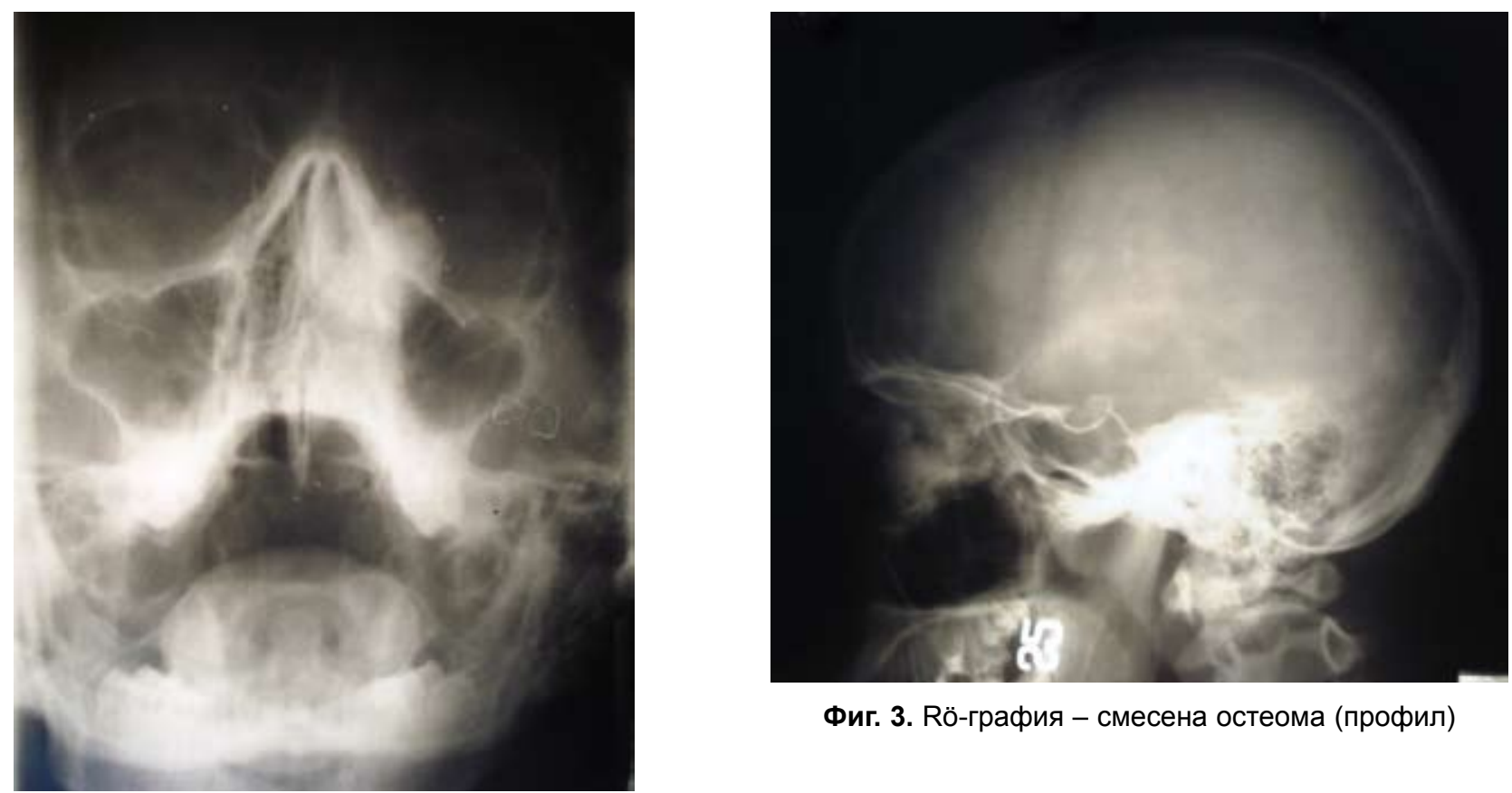

Фиг. 3. Rö-графия - смесена остеома (профил)

Фиг. 2. Rö-графия - смесена остеома (фрас)

\section{Образни изследвания - CT}

СТ демонстрира добре ограничена маса с променлива плътност, вариращи от много пльтна (подобно на плътността на нормално кортикал- на кост) до по-малко плътна с вид на матово стькло. Те се виждат като образувание, растящо в кухината на синуса или по-рядко екзофитно растящо извън синусите. 


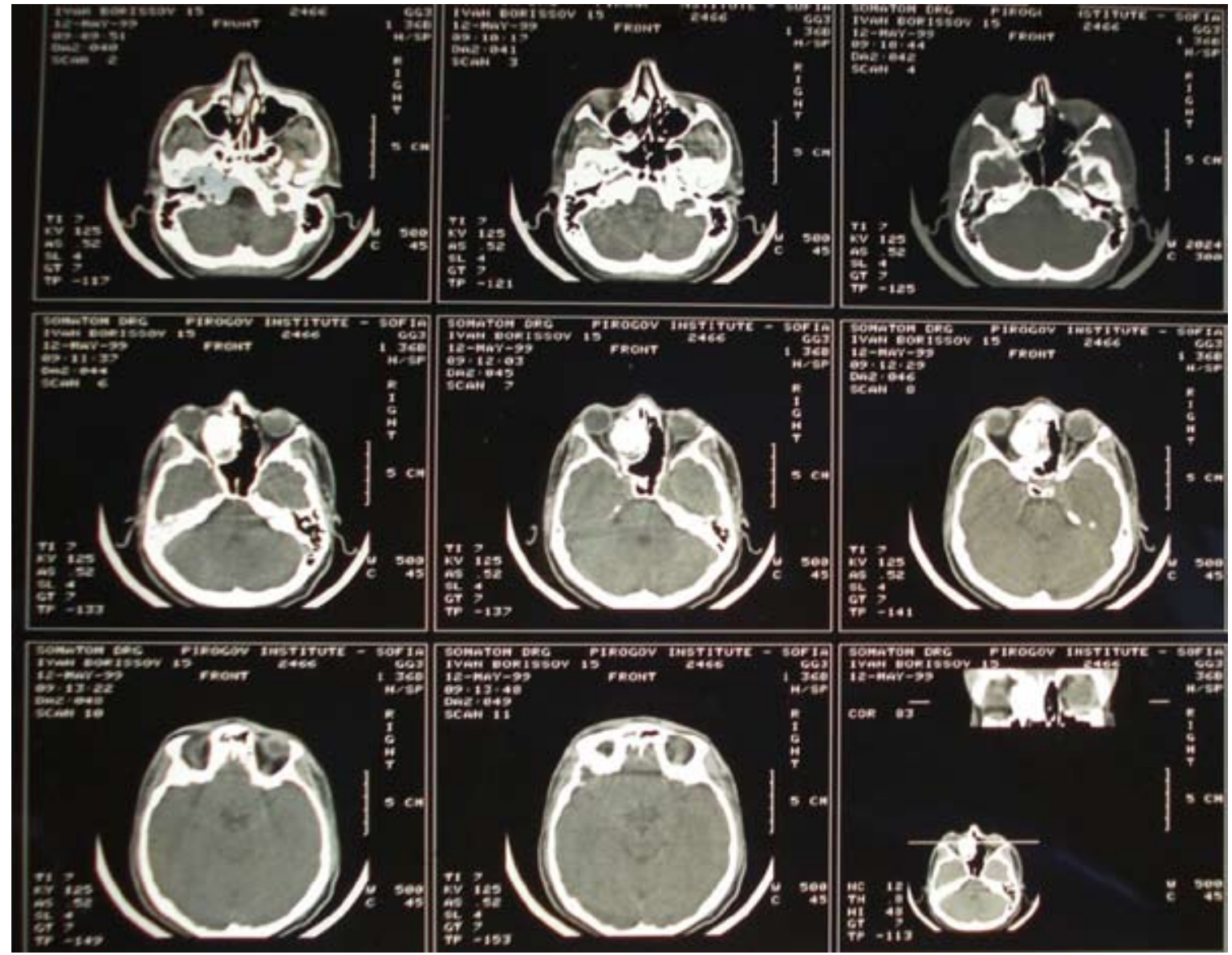

Фиг. 4. СТ-смесена остеома

\section{Образни изследвания - MRI}

Ha MRI пльтните-компактни остеоми са с ниськ интензитет за всички секвенции. Зрелите или компактни остеоми могат да се демонстрират със сигнал като костен мозък, но също са предимно с ниськ интензитет за всички секвенции.

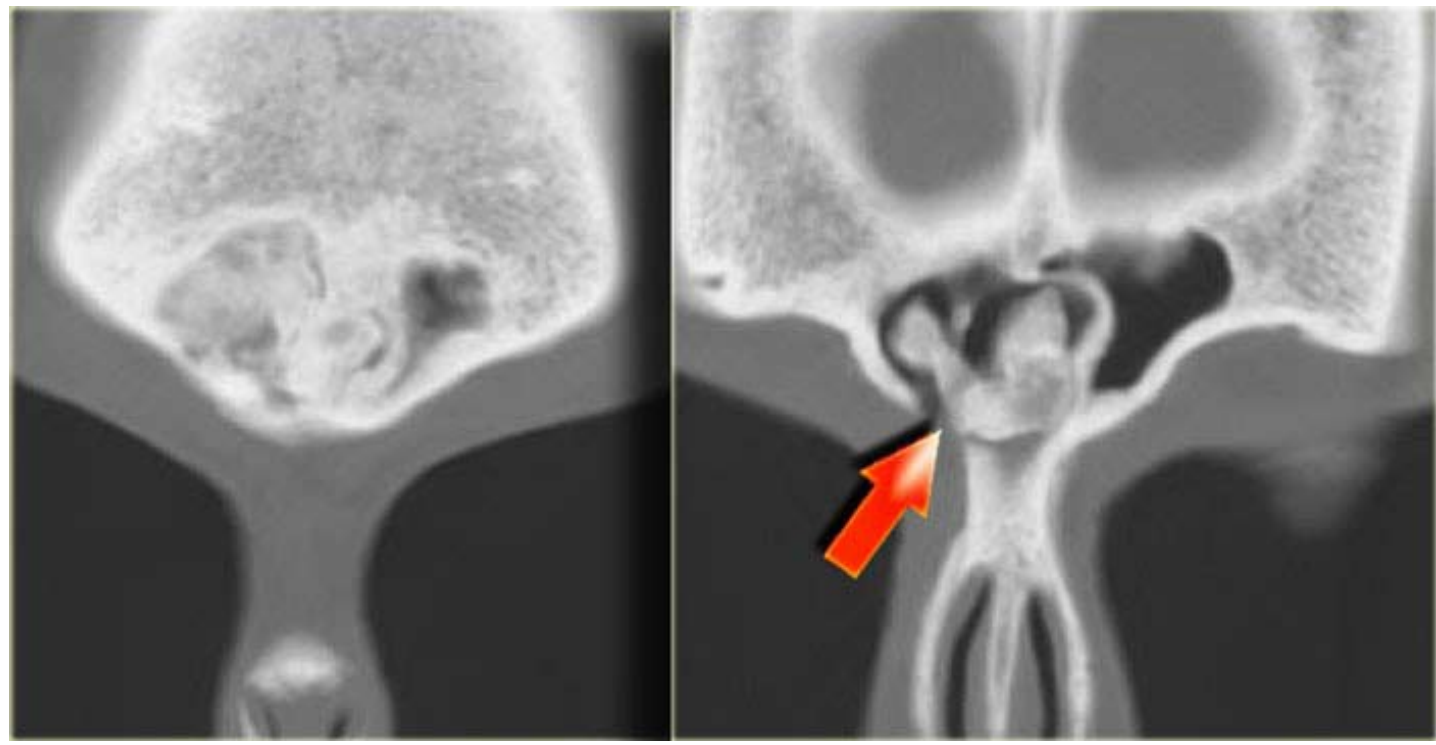

Фиг. 5. Paranasal Sinuses - MRI; Laurie Loevner and Jennifer Bradshaw; Radiologydepartment of the University of Pennsylvania, USA and the radiologydepartment the Medical Centre Alkmaar, the Netherlands 


\section{Лечение и прогноза}

В асимптомните случаи ексцизия не е задължителна и решението за хирургично лечение зависи от хирурга. Ако са налице симптоми от синоназалната област, тогава те могат първоначално да се потискат медикаментозно (както ако не съществува остеома). В случаите, когато остеомът се приема, че е отговорен за симптомите (напр. болка, синузит, мукоцеле или др.), тогава се налага извършване на резекция. Някои хирурзи предпочитат да отстранят всички установени остеоми. Ексцизия може да се извърши с външен достъп или ендоскопски.

\section{Диференциална диагноза}

В диференциално-диагностичен план на базата на образни изследвания се включват:

- фиброзна дисплазия - особено при остеоми с по-малка плътност - остеоми, изглеждащи рентгенографски тип матово стъкло

- Други остеогенни тумори

- остеобластома

- остеосаркома - по-често на горната челюст (по-често, отколкото максиларен синус или долна челюст)

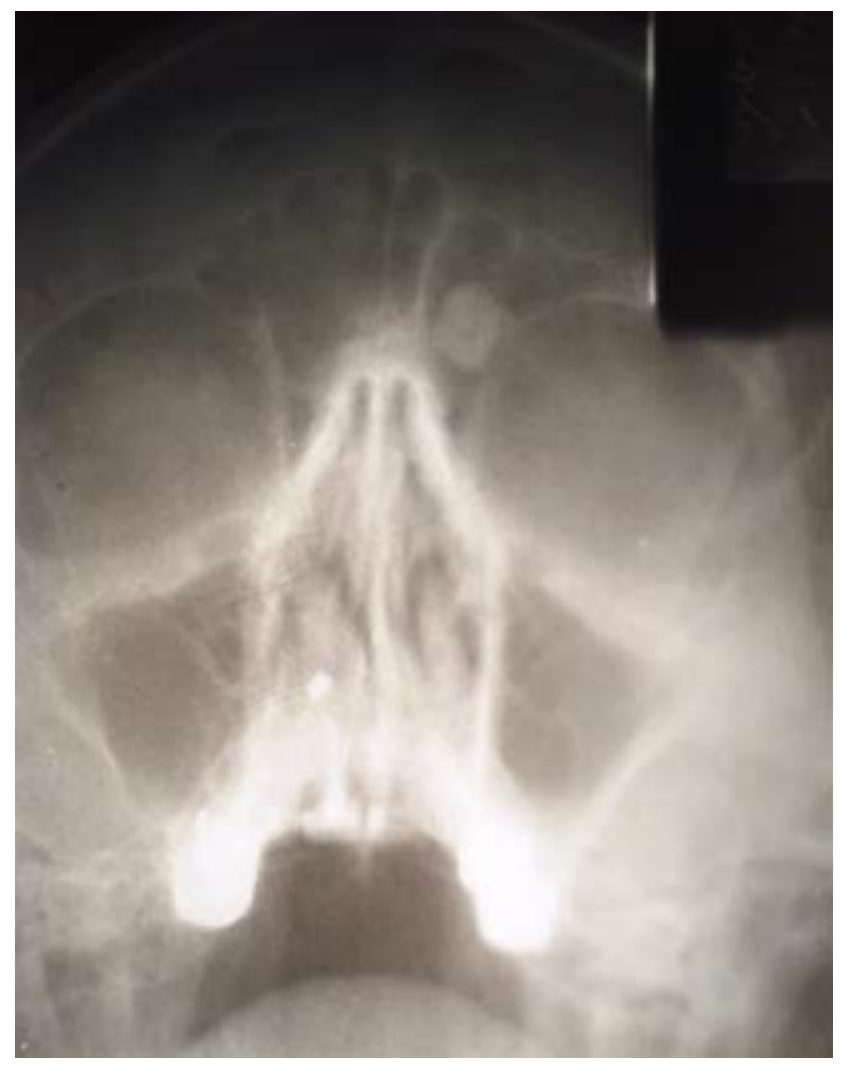

Фиг. 6. Предоперативна Rö-графия (клиничен случай)
- млади пациенти

- по-агресивен външен вид и бърз растеж

- цементо-осифицираща фиброма ${ }^{3}$

- обикновено на алвеоларни части на долната челюст или максилата

\section{Клиничен случай}

Касае се за 41-годишна пациентка с челно главоболие с давност повече от година, трудно повлияващо се от НСПВС. Не се е оплаквала от запушване на носа, ринорея или други симптоми, типични за околоносните кухини. Пациентката е консултирана от невролог (за изключване на главоболие от неврологичен характер), кардиолог (за изключване на високо кръвно налягане). Поради засилване на болката е насочена от УНГ за Rӧ-графия на околоносни кухини, на която се установява сянка с костна пльтност в рамките на фронталния синус вляво. Насочена в последствие за СТ на околоносни кухини, при което са установени данни за пльтен костен Ту. Пациентката е оперирана чрез отворен достьп. Оперативно лечение - Trepanatio sinus frontalis a modoBeck.

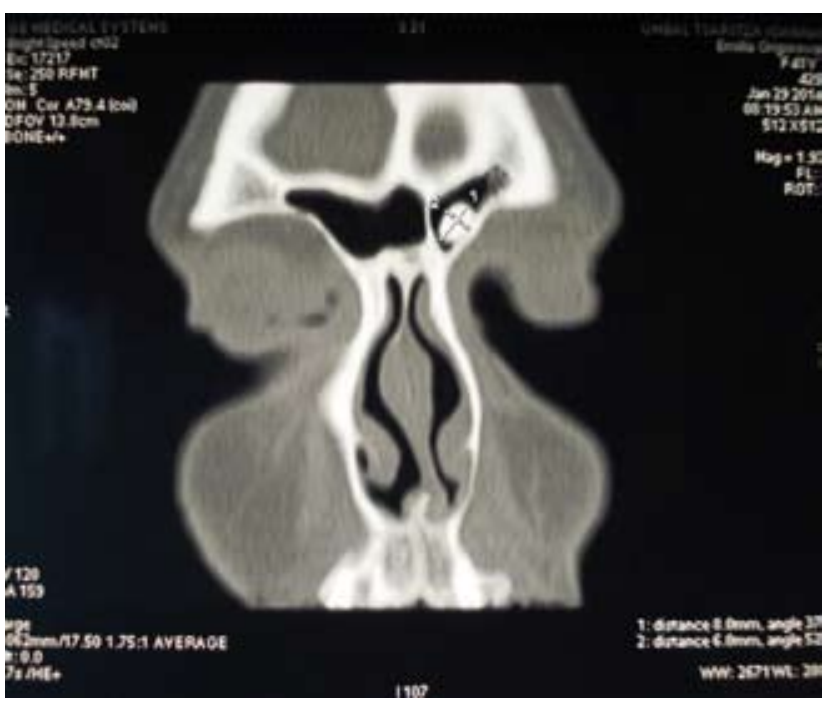

Фиг. 7. Предоперативна СТ - клиничен случай 


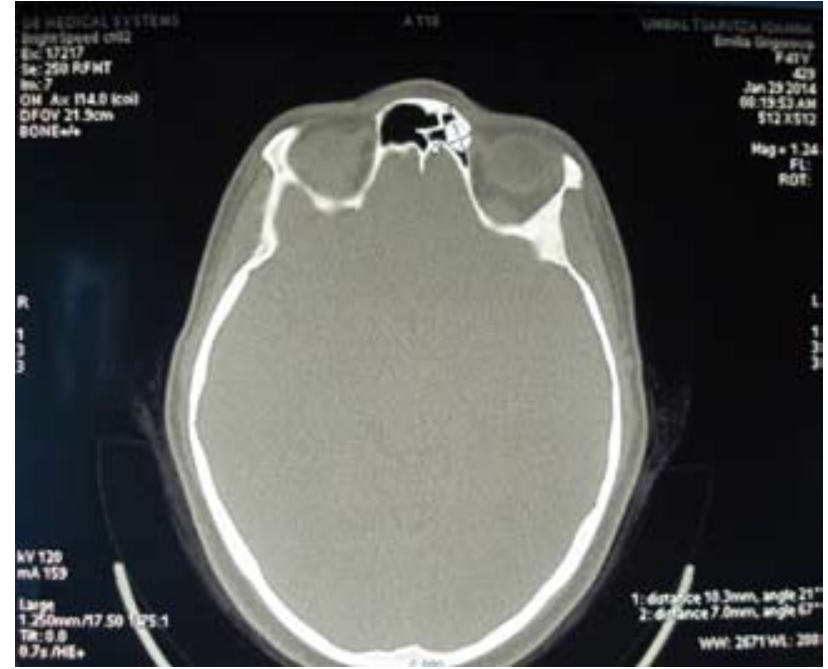

Фиг. 8. Предоперативна СТ - клиничен случай

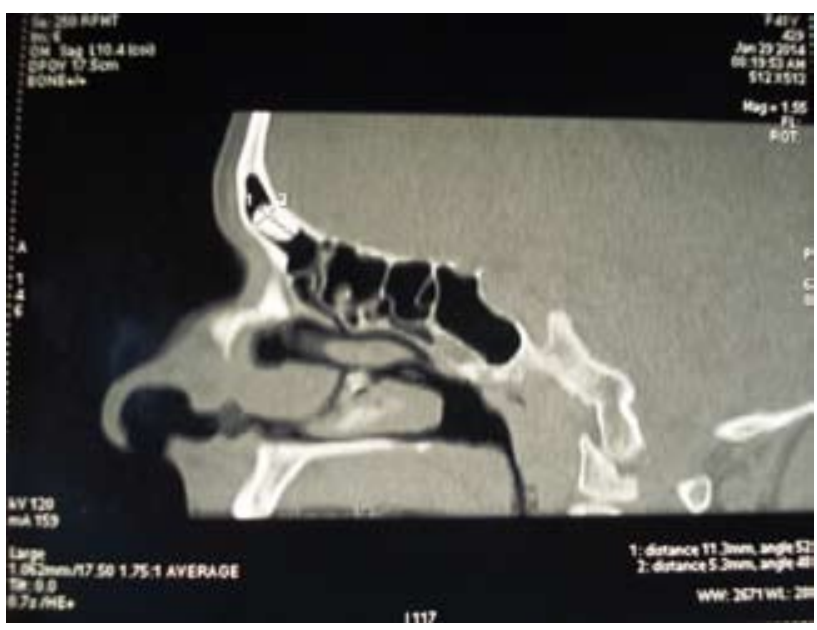

Фиг. 9. Предоперативна СТ - клиничен случай

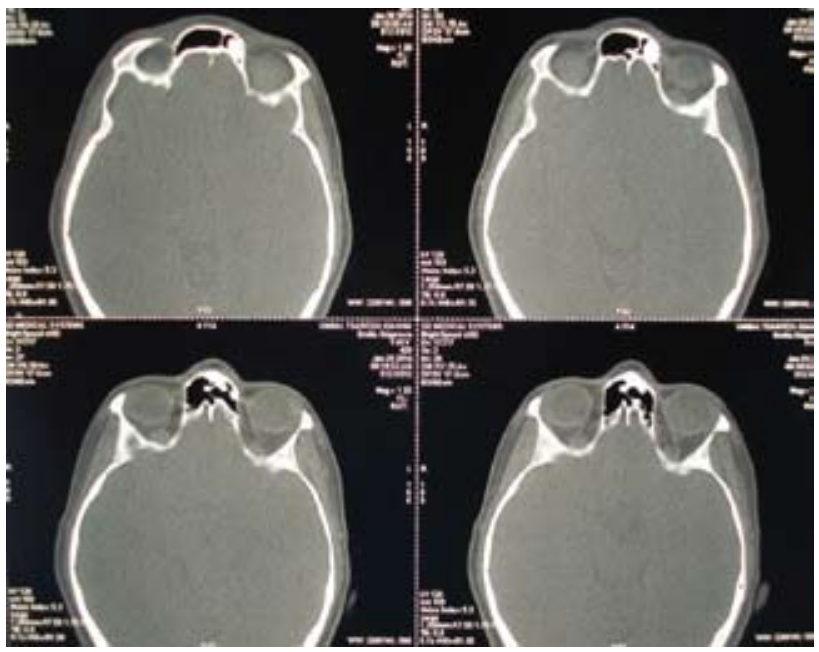

Фиг. 10. Предоперативна СТ - клиничен случай

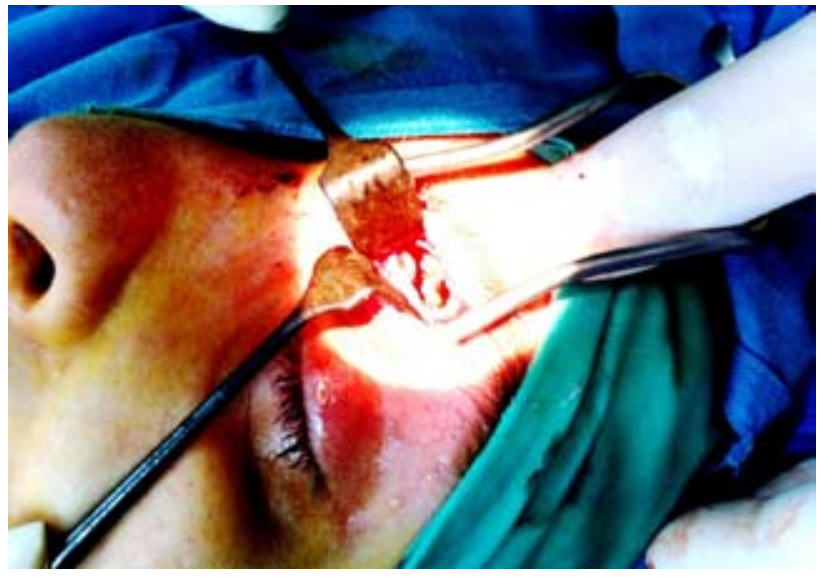

Фиг. 11. Оперативна интервенция

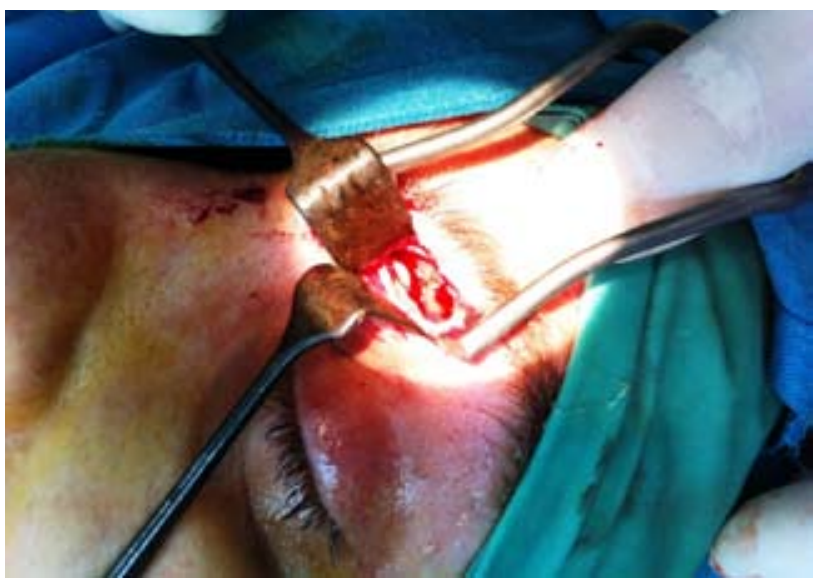

Фиг. 12. Оперативна интервенция

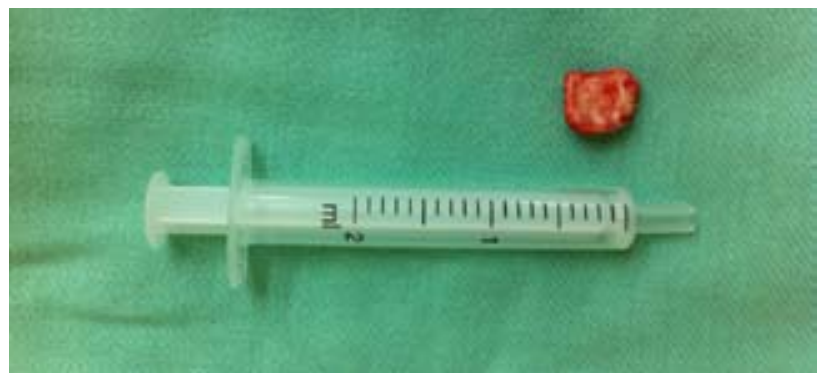

Фиг. 13. Следоперативна находка - остеом

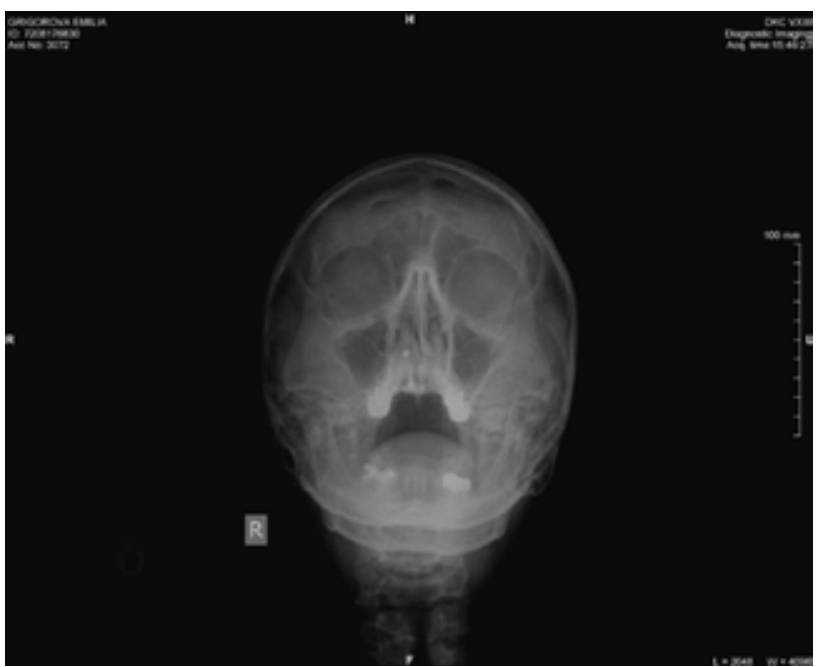

Фиг. 14. Следоперативна Rö-графия 


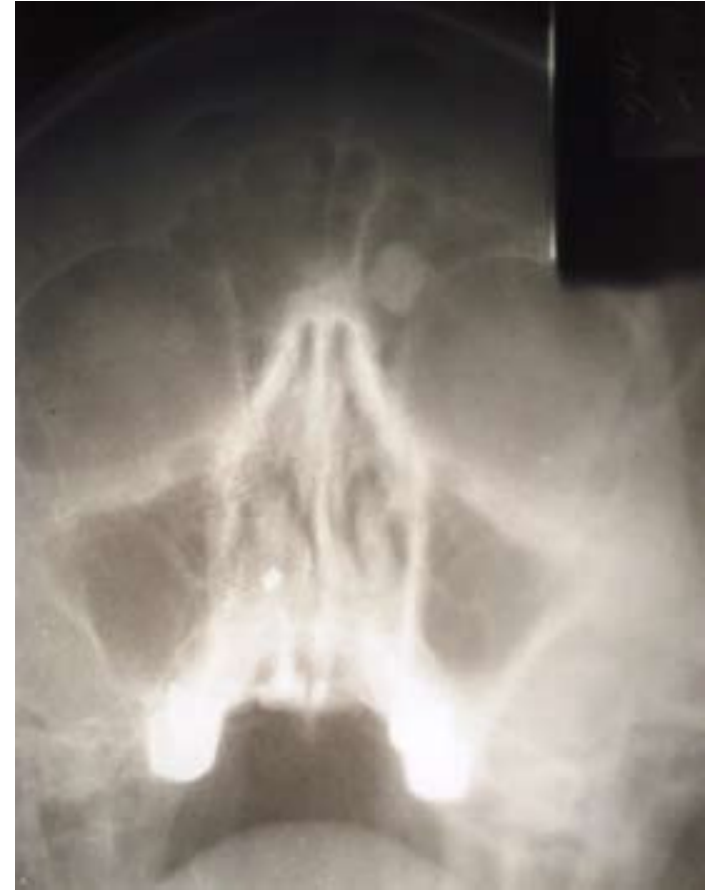

Фиг. 15. Rö-графия преди операцията

\section{Заключение. Обобщение}

Остеомите са най-често срещани тумори на околоносните синуси.

Най-често се наблюдават във фронтален синус и етмоидалните клетки.

Представляват доброкачествени костни тумори, произхождащи от мембранни елементи на костта, състоящи се от пльтна костна тъкан.

Мнозинството синусни остеоми се откриват случайно.

В зоната на черепа те обикновено възникват по повърхността на черепа.

Запушване на дренажните отвори на синусите може да доведе до възникване на инфекция

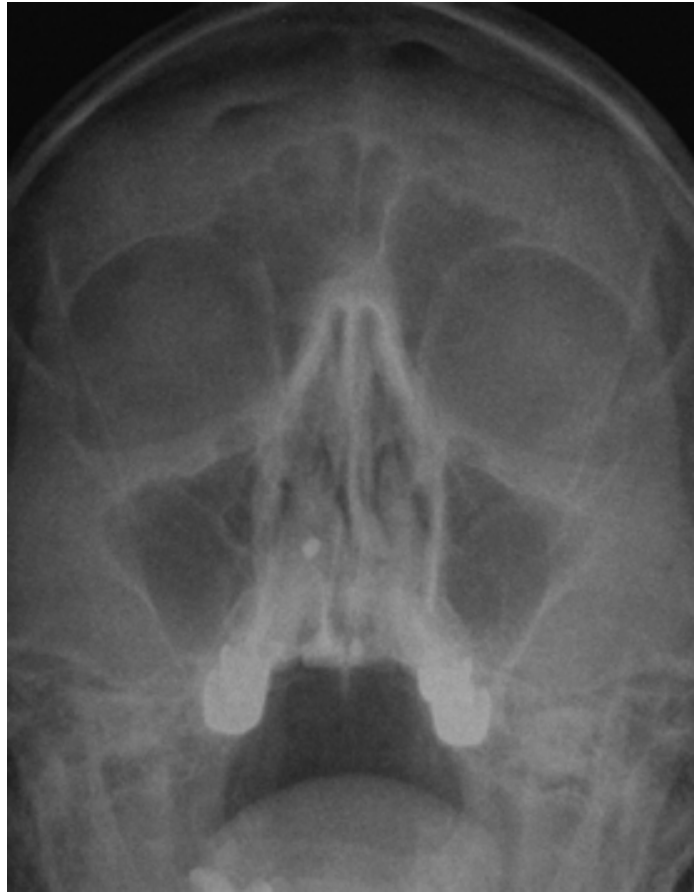

Фиг. 16. Rö-графияя след операцията

(синузит) или да предизвика образуване на мукоцеле.

Рядко голям костен тумор на фронталния и етмоидалния лабиринт може да измести очния булб напред и да причини proptosis.

Много рядко може да ерозира твърдата мозъчна обвивка, което да доведе до риноликворея и/или интракраниална инфекция.

Мултиплени остеоми често са асоциирани със Синдрома на Гарднер.

Ексцизията им може да става ендоскопски или хирургично, чрез отворен достъп.

Не е необходимо отстраняване на безсимптомните остеоми. Веднъж радикално отстранени, не рецидивират.

\section{Библиография}

1. Недев П, Ценев Ив, Марев Д, Ендоорбитален остеом. Международен бюлетин по оториноларингология 2006, бр. 2, 43-46;

2. Ценев, Ив.; Клинико-морфологична риноларингология; 2003; 202-203 стр.

3. Мелничаров, М., А. Джоров. Остеом на носната пирамида - късно усложнение след риносептопластика.- Военна медицина, 58, 2006, $3,50-51$.

4. Paranasal sinus osteoma; Dr MT Niknejad and Dr Frank Gaillardetal. / 1. Maroldi R, Nicolai P, Antonelli AR. Imaging in treatment planning for sinonasal diseases. Springer Verlag. (2005) ISBN:3540423834. Readitat Google Books - Finditat Amazon

5. Chen CY, Ying SH, Yao MS et al. Sphenoid sinus osteoma at the sella turcica associated with empty sella: CT and MR imaging findings. AJNR Am J Neuroradiol. 2008; 29 (3): 550-1. doi:10.3174/ajnr.A0935 - Pubmedcitation

6. Maxillofacial Imaging. T.A. Larheim, P.-L. Westesson. Springer ISBN:3540786856 (finditatamazon.com)

7. Hsu CC, Kwan GN, Bhuta SS. Non-traumatic cerebrospinal fluid rhinorrhea caused by ethmoid sinus osteoma. J Clin Neurosci. 2010;17 (9): 1185-6. doi:10.1016/j.jocn.2009.11.028 - Pubmedcitation

8. Kim KS. Frontal Headache Induced by Osteoma of Frontal Recess. Headache. 2013, Headache (fulltext) - doi:10.1111/head.12029 - Pubmedcitation

9. ENDOSCOPIC REMOVAL OF FRONTOETHMOID OSTEOMA: A CASE REPORT; Murat Sarı, Tekin Bağlam, Zahide Mine Yazıcı, Cüneyd Üneri; Department of Otorhinolaryngology, School of Medicine, Marmara University, İstanbul, Turkey; Marmara Medical Journal.

10. Malignant Tumors of the Sinuses; in eMedicine by Gerard Domanowski.

11. The Silent Sinus Syndrome by Anna Illneretal. AJR 2002; 178:503-506. http://www.ajronline.org/cgi/content/full/178/2/503

12. http://www.learningradiology.com/misc/contactlegalpage.htm 